will affect the output of motion detectors driven by rod signals. As a result, the relative signal at slow velocities will be higher than at fast velocities for rod vision, so the stimuli will appear slower.

The use of artificial lighting can help to avoid the disadvantages of rod-mediated vision. Indeed, most tasks can now be performed as well by night as they can by day. But driving at night may be an important exception. The region illuminated by the car headlights is processed mainly by the cones, whereas on a poorly lit road the remaining visual field is in the dark and is processed mainly by rods. The region in the dark includes the sides of the visual fields, where translatory motion signals are largest. This might lead to an underestimation of the speed of movement, which in turn might elicit a compensatory — and possibly fatal - increase in speed ${ }^{10}$.

Karl R. Gegenfurtner ${ }^{\star}$, Helmut Mayser $\dagger$, Lindsay T. Sharpe $\dagger$

${ }^{*}$ Max-Planck-Institut für biologische Kybernetik, Spemannstrasse 38, 72076 Tübingen, Germany e-mail:karl@kyb.tuebingen.mpg.de

$\dagger$ Universitätsaugenklinik, FEO,

Röntgenweg 11, 72076 Tübingen, Germany

1. Hess, R. F., Sharpe, L. T. \& Nordby, K. Night Vision: Basic, Clinical and Applied Aspects (Cambridge Univ. Press, 1990).

2. Takeuchi, T. \& De Valois, K. K. Vision Res. 37, 745-755 (1998)

3. Sharpe, L. T. \& Nordby, K. in Night Vision: Basic, Clinical and Applied Aspects (eds Hess, R. F., Sharpe, L. T. \& Nordby, K.).

335-389 (Cambridge Univ. Press, 1990).

4. Kohl, S. et al. Nature Genet. 19, 257-259 (1998).

5. Sharpe, L. T., Stockman, A., Jägle, H. \& Nathans, J. in Colour Vision: From Genes to Perception (eds Gegenfurtner, K. R. \& Sharpe, L. T. ) 3-48 (Cambridge Univ. Press, 1999).

6. Cavanagh, P. \& Anstis, S. Vision Res. 31, 2109-2148 (1991).

7. Thompson, P. Vision Res. 22, 377-380 (1982).

8. Hawken, M. J., Gegenfurtner, K. R. \& Tang, C. Nature 367, 268-270 (1994).

9. Barlow, H. B. J. Physiol. 141, 337-350 (1958).

10. Snowden, R. J., Stimpson, N. \& Ruddle, R. A. Nature 392, 450 (1998)

\section{Sexual propagation by sponge fragments}

Habitat fragmentation means that many species occur in discrete populations ${ }^{1}$, so it is important for sessile species to colonize new areas. It has not been clear how sponges whose larvae disperse over short distances achieve this. Fragments may break off sponges as a result of physical and biological disturbance and are then dispersed by currents and recruited as independent individuals or colonies ${ }^{2,3}$. Local populations are expected to have high genetic relatedness as a result, but most sponge populations have high levels of genetic variability ${ }^{4,5}$. We suggest that this discrepancy results from an interaction between fragmentation and sexual reproduction.

We studied reproduction in Scopalina lophyropoda, a sublittoral demosponge with

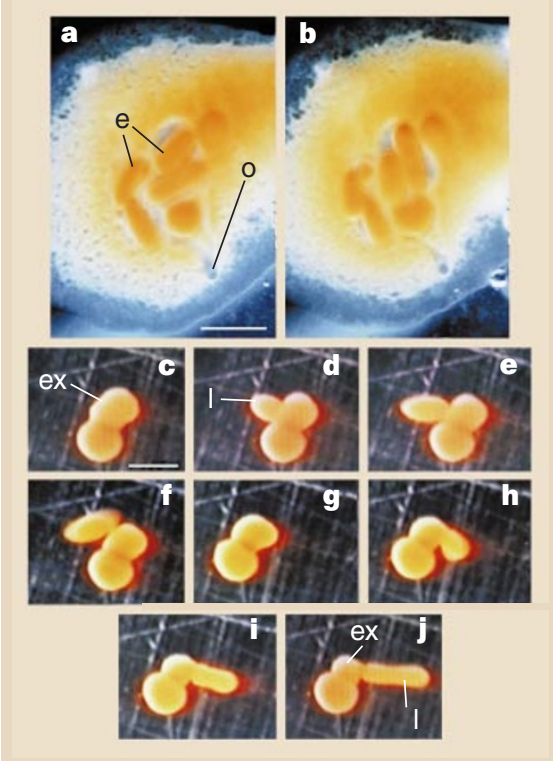

Figure 1 Time-lapse observations of embryogenesis and larval release. $\mathbf{a}, \mathbf{b}, \mathrm{A}$ small sponge reorganized from an explant. Six embryos (e) are incubated in a chamber connected to the exterior through an oscular tube (0). Note the differences in size and repositioning of embryos in the 90 min between pictures. $\mathbf{c}-\mathbf{j}$, Time-lapse observations over 93 min of two embryos escaping as free-swimming larvae from an unattached explant (ex), which is in contact with another non-histocompatible fragment. Scale bars, $1 \mathrm{~mm}$.

populations sparsely scattered over the western Mediterranean ${ }^{6}$. In this species, embryos are incubated and lecithotrophic parenchymella larvae are released from mid-July to late August. Because the planktonic phase lasts only 2.5 days, most larvae are believed to recruit locally. However, the dispersal potential of these larvae is significantly increased by the fragmentation of brooding adults as a result of wave action and foraging by fish and echinoderms.

Tissue shredded artificially reorganizes into dense balls, in which internal epithelia and choanocyte chambers dissociate and most specialized cells regress to an amoeboid, archaeocyte-like morphology. If detached fragments lie immobile on the substratum for a few days, they reattach and reorganize as functional sponges. When fragmentation occurs in reproductive sponges, fragments as small as 1 to $2 \mathrm{~mm}$ across may contain several developing embryos. Because development requires nourishment from specialized nurse cells through a placentalike membrane, we expected that the embryos would be reabsorbed and their energy reallocated to reorganize the colony. Instead, embryos were nourished by cells in the tissue fragment, where they completed development to free-swimming larva.

We used forceps to disintegrate sponges in early and late embryogenesis (one month before and 10 days after the onset of larval release), and randomly selected explants (balls of tissue) $1-2 \mathrm{~mm}$ across $(n=80$ per group). We found that $52.5 \%$ of the explants obtained in early embryogenesis remained embryogenically active and released a total of 102 free-swimming larvae (between 0 and 7 per explant) over a 28 -day period. The first two larvae were released on days 4 and 8, before the explants reorganized as sponges. The remaining embryos were incubated for 14-28 days in a translucent, atrium-like chamber formed once explants had reorganized into sponges (Fig. 1a). Nearly mature larvae moved around inside the chamber for several days before being released through an oscular tube (Fig. 1a,b). The atrium then lost its structure and the oscules regressed to being perforations.

When mother sponges in late embryogeny were shredded to obtain explants, most mature embryos escaped as free-swimming larvae. Only $6.25 \%$ of explants contained developing embryos, and just seven larvae were released over a 28-day period, escaping from unattached explants in all cases by crawling through the disorganized mass of cells in the explant (Fig. 1c-j).

Explant attachment took between 3 and 24 days in calm water, with just 2.5\% remaining unattached after 28 days, and these were apparently still viable. There were no significant differences in time to attachment between explants that carried embryos and those that did not. It is difficult to estimate possible dispersal distances before attachment, but large sponge fragments can disperse rapidly over several kilometres during heavy storms ${ }^{3}$.

Our results show that even small fragments often carry the essential functional elements for reorganizing and nourishing embryos. Our findings also indicate that fragmentation may interact with sexual reproduction. This means that the dispersal capacity of sexually produced propagules is maximized by the additional dispersal of the asexual propagule. The dispersal of embryo-bearing fragments also maximizes the chance that several distinct genotypes will reach a new area, increasing the chance of establishing new populations.

Manuel Maldonado, María J. Uriz

Centro de Estudios Avanzados de Blanes (CSIC), Department of Aquatic Ecology, Camino de Santa Bárbara s/n, Blanes 17300, Girona, Spain e-mail:maldonado@ceab.csic.es

1. Hanski, I. Nature 396, 41-49 (1998).

2. Battershill, C. N. \& Bergquist, P. R. in New Perspectives in Sponge Biology (ed. Rützler, K.) 397-403 (Smithsonian Institution Press, Washington DC, 1990).

3. Wulff, J. L. Coral Reefs 14, 55-61 (1995).

4. Solé-Cava, A. M, \& Thorpe, J. P. Mar. Biol. 93, 247-253 (1986).

5. Benzie, J. A. H., Sandusky, C. \& Wilkinson, C. R. Mar. Biol. 119, 335-345 (1994).

6. Uriz, M. J., Maldonado, M., Turon, X. \& Martí, R. Mar. Ecol. Prog. Ser. 167, 137-148 (1998).

7. Fell, P. E. in Reproductive Biology of Invertebrates Vol. IV, Oogenesis, Oviposition, and Oosorption (eds Adiyodi, K. G. \& Adiyodi, R. G.) 1-41 (Wiley, New York, 1989). 